\section{Medical school places: what will be the effect of lifting the cap?}

Last week the government announced it was temporarily lifting the cap on the number of medical school places in England, after A level students who were unable to sit exams because of covid were awarded grades based on teachers predictions. Abi Rimmer examines the fallout

Abi Rimmer

\section{What does the announcement mean for students?}

The Department of Health has said that where students have met their offer to study at a medical school they should be able to take up that place this year or be guaranteed a place at their chosen medical school in 2021-22. Additional teaching grant funding will be provided to medical schools that take on extra students.

\section{What was the cap on medical school places?}

Before the cap was lifted, places were limited to around 7500 in England and 9500 in the UK. The figure for England previously stood at 6000 but was increased by Jeremy Hunt during his tenure as health secretary.

\section{What does lifting the cap mean for medical schools?}

Medical schools routinely make more offers than they have places, by around $20 \%$, because they know that around $44 \%$ of students will not achieve their predicted grades. ${ }^{2}$ The Medical School Council has estimated that because students have been awarded their predicted grades this year around 1600-2000 extra places will be needed. This means medical schools are expected to take on more students this academic year, award deferred places for next year, or both.

\section{Will all these students cope at medical school?}

The MSC has warned that awarding all students their predicted grades could result in "a higher likelihood of a greater than usual failure rate as students progress through their very demanding studies." ${ }^{2}$ Chris McManus, professor of psychology and medical education at University College London, and colleagues have conducted research that shows that A level exam results, rather than predicted grades, are the better predictor of how well a student will perform at medical school. ${ }^{3}$ Their results indicate that students whose predicted grades were higher than the grades they would have achieved if they sat their exams may struggle. "We know there are always some students who are challenged by medical school," McManus says. "It is a really hard course. When people let in students with lower A level grades they tend to do less well. There is little doubt about that."

\section{How will medical schools cope with these extra students?}

David Strain, co-chair of the BMA's academic staff committee and a senior clinical lecturer at the University of Exeter Medical School, warns that many universities are already struggling. "In six weeks' time we are going to have up to $20 \%$ more medical students in universities that are desperately trying to get people back into some sort of lecture programme, while knowing that we don't have the space for physical distancing," he said. Medical schools are also suffering from a declining clinician academic workforce, with senior lecturer numbers falling by $27 \%$ since $2004 .{ }^{4}$ Strain warns that the decline is now being coupled with cuts to hours and, in some places, cuts to jobs. "We are seeing clinical academics being asked if they would defer their pay rises this year, as well as voluntary early retirement and voluntary redundancy schemes," he said.

\section{Why are universities struggling?}

The covid-19 pandemic has had a huge effect on universities' finances, Strain says. “Universities haven't been applying for grants because of the current environment, and the covid-19 studies that are being done are being done at a loss because the National Institute for Health Research only pays $80 \%$ of the total cost of the study," he says. "Some universities have also handed back student bursaries and accommodation fees, as well as losing fees from international students. Charitable incomes have also fallen because of the pandemic."

All this means that universities will potentially be in the red by hundreds of millions of pounds at the start of the new term, Strain warns.

\section{What does the government's promised funding for the extra students cover?}

Though an increase in teaching grant funding has been promised, it is unclear whether there will be extra funding for the additional students' clinical placements. The health department has said that work is being done to ensure that clinical placements would be available for these additional students but did not respond to questions from The BMJ about how placements would be funded. 


\section{Will there be foundation training posts for these extra students?}

The BMA has warned that if future foundation training post numbers do not align with medical graduate numbers, the foundation training programme will once again be oversubscribed or, worse, graduates could be left unemployed. ${ }^{5}$ Katie Petty-Saphon, chief executive of the MSC, says that the decision to lift the cap on medical school places came with the understanding that it would result in additional capacity being required in postgraduate training as well. "In the discussions that we have been having with the Department of Health and Health Education England it's clear that if you take on additional students this year then you are looking at 10 to 12 years of education-undergraduate and postgraduate," she says.

But Strain said the BMA was concerned, on the basis of past experience, that it would not get the guarantees it wanted. "Part of the problem we are anticipating is that when Jeremy Hunt expanded medical school places we asked if there would be an expansion of foundation training posts, and he said that he couldn't make assurances for another government as there would be an election in that time," Strain said. "There will, of course, be another election before this year's cohort graduates."

1 Torjesen I. Hunt aims for fully home grown doctor workforce. BMJ2016;355:15399. doi: 10.1136/bmj.i5399 pmid: 27702756

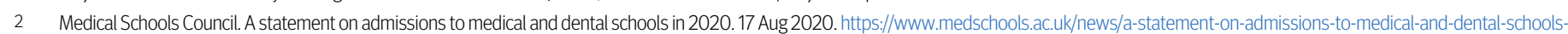
in-2020.

3 McManus IC, Woolf K, Harrison D, et al. Calculated grades, predicted grades, forecasted grades and actual A-level grades: reliability, correlations and predictive validity in medical school applicants, undergraduates, and postgraduates in a time of COVID-19. medRxiv 2020.06.02.20116830. https://doi.org/10.1101/2020.06.02.20116830.

4 Medical Schools Council. Clinical academic survey. https://www.medschools.ac.uk/clinical-academic-survey.

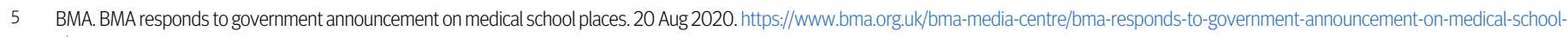
places.

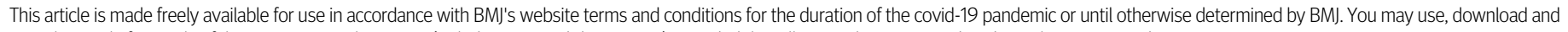
print the article for any lawful, non-commercial purpose (including text and data mining) provided that all copyright notices and trade marks are retained. 